\title{
Rosettes, Remingtons and Reputation: Establishing potential determinants of leopard (Panthera pardus) trophy prices across Africa
}

\author{
Alexander R. Braczkowski ${ }^{1 \star}$, Guy A. Balme ${ }^{2,3}$, Amy Dickman $^{1,4}$, David W. Macdonald ${ }^{1}$, \\ Paul J. Johnson ${ }^{1}$, Peter A. Lindsey ${ }^{2,5}$ \& Luke T.B. Hunter ${ }^{2,6}$ \\ ${ }^{1}$ Wildlife Conservation Research Unit, Department of Zoology, University of Oxford, Oxford OX13 5QL, U.K. \\ ${ }^{2}$ Panthera Foundation, 8 West 40th Street, 18th Floor, New York, U.S.A. \\ ${ }^{3}$ Department of Zoology, University of Cape Town, Rondebosch, 7701 South Africa \\ ${ }^{4}$ Ruaha Carnivore Project, P.O. Box 1275, Iringa, Tanzania \\ ${ }^{5}$ Mammal Research Institute, Department of Zoology and Entomology, University of Pretoria, Pretoria, South Africa \\ ${ }^{6}$ School of Life Sciences, University of KwaZulu-Natal, South Africa \\ Received 25 October 2014. To authors for revision 14 January 2015. Accepted 30 July 2015
}

In a number of African countries, the trophy hunting of large felids is an important revenue generator for landholders, governments and in some cases communities. The hunting of large felids is especially profitable but they are sensitive to harvest, as the killing of prime-aged, dominant males can lead to infanticide and lowered reproductive success. In an attempt to limit the negative impacts of trophy hunting on large felids, the scientific community has proposed a number of interventions, including age restrictions on the animals that may be hunted. Such interventions are theoretically complementary to trophy hunting, as hunters typically seek large trophies, and older animals are normally larger than younger ones in large felids. If trophy size results in an increase in trophy price, then interventions that improve average trophy size could confer elevated earnings. This is particularly true if such interventions increased the number of failed hunts such that the same tag can be sold more than once. However, if trophy size is not one of the most important factors determining the desirability of a hunt (which we judge by the price paid for a trophy hunt package), it may be more difficult to implement such schemes. It is therefore important to evaluate potential determinants of trophy hunt package price; and we examine that here for leopards (Panthera pardus) in Africa, at both the country and outfitter level. We show that Tanzania and Botswana have the most expensive package prices while South Africa has the cheapest packages. At the country level, we found no statistical relationships between package price and leopard trophy size (either through advertised website or Safari Club International (SCI) leopard trophy size), country GDP, relative hunt success, or quota size. Contrastingly, the number of charismatic species offered within a package and an index of outfitter reputation (as measured by total $\mathrm{SCI}$ trophy records) were positively associated with package price. Interestingly, SCl leopard trophy size was inversely correlated with package price. Our results suggest that hunters do not value leopard trophy size above other factors, which could hinder the implementation of more sustainable, age-based leopard hunting regulations.

Key words: leopard, economics, trophy hunting, sustainability, Africa.

\section{INTRODUCTION}

Trophy hunting is a commonly used tool to generate income from many terrestrial mammals worldwide (Harris \& Pletscher, 2002; Milner et al., 2006). However, its use is increasingly debated, particularly

*To whom correspondence should be addressed.

E-mail: alexander.braczkowski@gmail.com when large, charismatic and threatened species are concerned (Lindsey, Balme, Booth \& Midlane, 2012). To date, several studies have suggested that the selective harvest of a few individuals may confer conservation benefits by providing economic justification for the retention of large tracts of land for wildlife, by creating incentives for wildlife-based land uses, and by generating funding for 
wildlife management (Lewis \& Alpert, 1997; Bond et al., 2004; Lindsey, Roulet \& Romanach, 2007).

The wildlife authorities of several countries, such as Tanzania, Zambia and Zimbabwe generate high proportions of their operating income from trophy hunting (Nelson, Lindsey \& Balme, 2013). However, using trophy hunting for revenue generation can create conflicts of interest whereby wild life authorities tend to set quotas at high levels to maximize their income (Nelson et al., 2013; Lindsey et al., 2014). Excessive quotas can lead to population declines which can be compounded by other forms of mortality, such as non-parental infanticide (Loveridge, Searle, Murindagomo \& Macdonald, 2007; Balme, Slotow \& Hunter, 2009; Swanepoel, Lindsey, Somers, van Hoven \& Dalerum, 2014). Excessive off-takes in hunting blocks can also result in negative impacts on populations in adjacent fully protected areas (Balme et al., 2010). Trophy hunting may also have genetic impacts over time and lead to a decrease in the size of the heritable secondary sexual traits selected for by hunters (Coltman et al., 2003; Von Brandis \& Reilly, 2007).

An understanding of how hunters value wildlife could contribute to its efficient management. The economic framework that underpins trophy hunting has been the focus of considerable recent research. The majority of this research has been on topics such as the significance of the industry to local economies (Lindsey et al., 2007; Samuelsson \& Stage, 2007; Saayman, Merwe \& Rossouw, 2011; Wenzel, 2011), species-specific contributions to the hunting industry (Lindsey et al., 2012; Lindsey et al. 2013; Jorge, Vanak, Thaker, Begg \& Slotow, 2013) and determinants of trophy price at the interfamily level (e.g. Johnson, Kansky, Loveridge \& Macdonald, 2010). There have also been numerous studies that have investigated price-rarity correlations of popularly hunted species (e.g. Johnson et al., 2010; Palazy, Bonenfant, Gaillard \& Courchamp, 2011, 2012).

Less is known concerning the factors that govern the price of wildlife species available in hunt packages. Determining which factors influence perceived value is important for assessing how changing trophy hunting regulations is likely to affect demand and revenue. There is now strong support for age-based systems being the most effective mechanism for the sustainability of large cat hunting (e.g. Whitman, Starfield, Quadling \& Packer, 2004; Packer et al., 2009). These models have shown that operation of an age-based sys- tem ensures a supply of older males, which can be harvested sustainably. In principle, this would work well for trophy hunting of felids, as hunters often seek to remove the largest individuals, and individuals get larger with age (e.g. Whitman et al., 2004; Dusty Joubert, unpubl. data). Intuitively, one would expect hunters to be more inclined to follow age-based hunting regulations (i.e. hunt an older animal) if they place particularly high value on the resultant trophy. Good trophies should naturally have a high value, and this is indeed the case for African elephant (Loxodonta africana) bulls, whose trophy fees increase linearly with the weight of their ivory (Booth, 2009). If this were the case for other species, trophy price could be an important tool for reinforcing sustainable practices (and thus, conservation outcomes). If it is not, this potentially undermines sustainability, and may require revision.

In this paper we aim to identify potential determinants of trophy package price at the species level for the African leopard (Panthera pardus). The leopard has the widest habitat tolerance and distribution of any Old World felid (Nowell \& Jackson, 1996) and occurs in tropical forests, savannas, true deserts and even human-dominated landscapes (Bailey, 1993). Despite this wide range it is thought to be in a state of decline (Ray, Hunter \& Zigouris, 2005), mainly due to anthropogenic persecution in retaliation to stock depredation, the illegal skin trade and poorly managed trophyhunting (Hunter, 2012; Swanepoel et al., 2014). Poorly managed trophy hunting is a particularly important source of mortality in leopard populations, as leopards have naturally high rates of infanticide (e.g. Balme, Hunter, \& Braczkowski, $2012 ; 40 \%$ in a protected population in the SabiSands). This is exacerbated by trophy hunting and may cause rapid population declines by artificial turnovers of adult males (Balme et al., 2009b). However, leopards are a key species for the hunting industry and contribute to economic incentives for land retention for wildlife, funding for wildlife management, and in some cases, may foster increased tolerance for leopards, particularly where depredation of livestock and valuable game is an important land use (e.g. Funston, Groom \& Lindsey, 2013; Swanepoel et al., 2014).

We use the leopard as a model species for three reasons: (i) leopard hunting has increased exponentially over the previous 30 years (Palazy et al., 2011), (ii) the price of leopard hunts has increased faster than for any other species (Lindsey et al., 
2012) and (iii) the majority of leopard hunting takes place in seven African countries (Balme et al., 2010), and there is considerable potential to detect variation in the package prices set by outfitters. We use a sample of leopard hunt package prices (obtained from the websites of hunting outfitters), to explore the variation in trophy package price at the outfitter level because the prices paid by hunters are all-inclusive and include trophy fees, daily rates and landowner fees. We also explore price variation at the country level in order to examine several important macro-economic effects such as market competitiveness and country stability. We then attempt to explain variation in leopard hunt package price.

\section{METHODS}

\section{Leopard trophy package price}

Since the United States of America (U.S.A.) is the largest market for African trophy hunting safaris and the majority of hunts are sold at hunting conventions (Lindsey et al., 2012), we believe that these trophy package prices will be representative of worldwide leopard trophy package prices. The Dallas and Houston Safari clubs are the two largest hunt clubs in the world and their exhibitions are where the majority of hunters advertise their hunts/packages. As price is often accepted as a measure of economic value in traditional market economies, we used the price of leopard trophy hunt packages as a proxy of their attractiveness and value to hunters (Lindsey et al., 2007). Leopard hunts are typically sold as part of a hunting pack- age (Leader-Williams, Kayera \& Overton, 1996) where a standard daily fee (which includes accommodation and logistic costs) is charged regardless of the success of the hunt over a fixed minimum number of days. If the hunt is successful, the client is also charged a trophy fee, which is typically set by the local conservation authority. We used price information from the seven main leopard hunting countries, omitting the smaller hunting countries from analyses as they contribute minimally to leopard trophy exports (see CITES online database; http://www.unep-wcmc-apps.org/citestrade \& Table 1).

\section{Statistical analysis}

Leopard trophy package price was thought a priori likely to be determined by three key variables, namely hunt duration, the outfitters daily rate, and the government-determined trophy fee. We commenced our analysis examining how these factors varied between countries. Package price in US dollars was used as the response variable in general linear models (GLM) with each of the three price components as predictor variables. We then did a series of post hoc Tukey tests to isolate where these differences lay.

\section{Country-level package price model}

Secondly, we postulated that leopard package price could be affected by a number of countrylevel variables, namely:

(i) Gross Domestic Product (GDP). We investigated the relationship between package price and

Table 1. Country size, CITES quota size and mean trophy exports for the 2006-2010 period obtained from the CITES database.

\begin{tabular}{|c|c|c|c|}
\hline Country & Country size $\left(\mathrm{km}^{2}\right)$ & Quota & 5 year mean export \\
\hline Botswana & 600370 & 130 & $44.0 \pm 6.69$ \\
\hline Central African Republic & 622984 & 40 & $23.6 \pm 6.67$ \\
\hline Ethiopia ${ }^{\varepsilon}$ & 1127127 & 500 & $0^{\varepsilon}$ \\
\hline Kenya $\$$ & 582650 & 80 & $0^{\$}$ \\
\hline Malawi* & 118480 & 50 & $0^{*}$ \\
\hline Mozambique & 801590 & 120 & $37.0 \pm 2.81$ \\
\hline Namibia & 825418 & 250 & $197.4 \pm 32.46$ \\
\hline South Africa & 1219912 & 150 & $114.2 \pm 11.73$ \\
\hline Tanzania & 945203 & 500 & $280.4 \pm 28.18$ \\
\hline Zambia & 752614 & 300 & $68.8 \pm 6.21$ \\
\hline Zimbabwe & 390580 & 500 & $251.4 \pm 11.72$ \\
\hline Uganda & 236040 & 28 & $1 \pm 1$ \\
\hline
\end{tabular}

${ }^{£}$ Ethiopia has no records of exports/imports in the CITES database and at present leopards are not hunted there (Hans Bauer, pers. comm.).

\$Kenya allow the export of leopard body parts but trophy hunting was outlawed in 1977.

*There were no leopard export records found in the CITES database for the 2006-2010 period in Malawi.

Namibia, Botswana, South Africa, Zimbabwe, Mozambique, Tanzania and Zambia were the countries used in our analysis. 
a country's GDP, as GDP is a recognized measure of a country's material standard of living.

(ii) Mean number of charismatic species included in leopard packages for a particular country. We hypothesized that countries with a higher number of charismatic species offered in leopard hunt packages would on average feature higher package prices. Charismatic species are defined as large, popularly hunted mammal species including sable antelope (Hippotragus niger), buffalo (Syncerus caffer), elephant, and lion (Panthera leo).

(iii) Safari Club International (SCl) leopard trophy size. We obtained information on leopard trophy size using the approach of Von Brandis \& Reilly (2007) and Lindsey et al. (2012). These authors obtained antelope and lion trophy sizes from the $\mathrm{SCl}$ record book and we replicated this for leopards, calculating the average leopard trophy sizes in decimal inches for the seven countries in our analysis. We hypothesized that because hunters often seek to shoot the largest individuals, countries with the largest trophies would have the most expensive packages.

(iv) Advertised leopard trophy size. Leopard trophy size was also assessed by estimating the ages of leopards displayed on outfitter's online trophy galleries. Balme et al. (2012) demonstrated that leopards could be accurately aged using morphological characteristics (e.g. dewlap size, facial scarring, ear wear) featured in photographs. Four assessors, each with extensive leopard aging experience, were asked to assign leopard trophy photographs from outfitter websites to one of four age categories (Balme et al., 2012): (1) 1 = leopards of $<2$ years; (2) $2=2-3$ years; (3) $3=4-6$ years; and (4) $4=>7$ years. Older and larger leopards thus achieve scores closer to 4 on this ordinal scale. We used the median score recorded for each outfitter and then used the median of all outfitters by country. The magnitude of differences is not easily interpreted on this scale and we aimed only to evaluate the direction of effects. We assessed only those outfitter websites with more than three leopard trophy photographs. We included only advertised trophy size as a country-level variable because many outfitters had few or no leopard trophy photographs on their websites. Although leopard hunt success rates, especially for large male leopards are often low, we assume that trophy hunters are likely to place their better trophy photographs on websites.

(v) Relative hunt success. We hypothesized that the likelihood of securing a leopard trophy may influence hunt package price. We therefore estimated relative leopard hunt success at a national level from 562 post-hunt register forms submitted by hunting clients that hunted with 228 outfitters between 1998 and 2010 (see www.huntingreport.com; accessed 1 November 2013). Hunt reports include information on the species hunted, hunting method used, hunt duration, and the success of hunts (Table 2). We derived hunting success by dividing the number of successful leopard hunts per country by the total number of leopard hunts reported per country. This would ideally be an outfitter-level variable; however, those outfitters for which we had price data were poorly represented in the hunt return form dataset.

(vi) CITES quota. We used the 2010 CITES leopard quotas as a coarse measure of leopard availability.

Table 2. Mean number of wildlife species hunted during a leopard hunt along with mean hunt durations for the seven main leopard hunting countries in Africa.

\begin{tabular}{lrcc}
\hline Country & $n^{*}$ & $\begin{array}{c}\text { Mean duration of } \\
\text { leopard hunt (days) }\end{array}$ & $\begin{array}{c}\text { Mean number of } \\
\text { species hunted }\end{array}$ \\
Botswana & 15 & $18.33 \pm 1.91$ & $4.6 \pm 0.79$ \\
Mozambique & 20 & $15 \pm 1.34$ & $5 \pm 0.64$ \\
Namibia & 71 & $13 \pm 0.47$ & $5.63 \pm 0.42$ \\
South Africa & 28 & $14.5 \pm 1.17$ & $4.92 \pm 0.57$ \\
Tanzania & 137 & $21 \pm 0.73$ & $8 \pm 0.3$ \\
Zambia & 50 & $18.32 \pm 0.87$ & $7.8 \pm 0.45$ \\
Zimbabwe & 241 & $15.29 \pm 0.43$ & $4.82 \pm 0.19$ \\
Grand total & 562 & $16.63 \pm 3.31$ & $4.99 \pm 0.13$ \\
\hline
\end{tabular}

*Information obtained from 562 post-hunt register forms collected over the 1998-2010 hunting period from 228 outfitters (obtained from the hunting report; www.huntingreport.com). 
(viia) The number of tourists visiting a country per year. We used the number of tourist visits (sourced from the United Nations World Tourism Organization tourism highlights 2013; Table 3 ) as a metric of country attractiveness. We hypothesized that if hunters were to hunt in attractive countries, then price would increase with the number of visits per country (e.g. hunters would be drawn to places with more tourist visits).

(viib) Failed states index ranking. Numerous authors have recognized that political instability is a major driver deterring tourists from visiting subSaharan Africa (e.g. Ankomah \& Crompton, 1990; Sönmez, 1998; Beirman, 2003). Contrastingly, Lindsey et al. (2007) suggested hunters are less sensitive to the factors which deter typical tourists from visiting sub-Saharan Africa. We also hypothesized that package price would be cheaper in countries with more political instability (therefore a higher failed states index). For this we used a country's Failed States Index ranking for the 2010 year (see: ffp.statesindex.org/rankings-2010sortable ; accessed 1 November 2013). The Failed States Index is a ranking based upon 12 indicators of state vulnerability and includes inter alia measures of economic decline, criminalization and refugee movements.

(viii) Outfitter market crowdedness. We included a measure of how many hunting outfitters were present in each country. We hypothesized that countries with a lower number of outfitters would feature higher package prices due to monopolization of the market.

We tested each of these variables independently by building a set of independent general linear models (GLM). We used a country's mean package price as the response variable and then used each of these variables as predictor variables.

\section{Outfitter-level package price model}

We were interested in explaining the variation in total package prices advertised across our sample of leopard hunting outfitters. We therefore hypothesized that package price would be influenced by four variables, one of which has two related parts; namely:

(i) Foreign or local outfitter. In some countries, the majority of hunting is conducted by professional hunters $(\mathrm{PH})$ that are brought in from other countries, due to a low availability of local hunting guides. One would expect the sourcing of international PHs to elevate the price of hunting safaris.

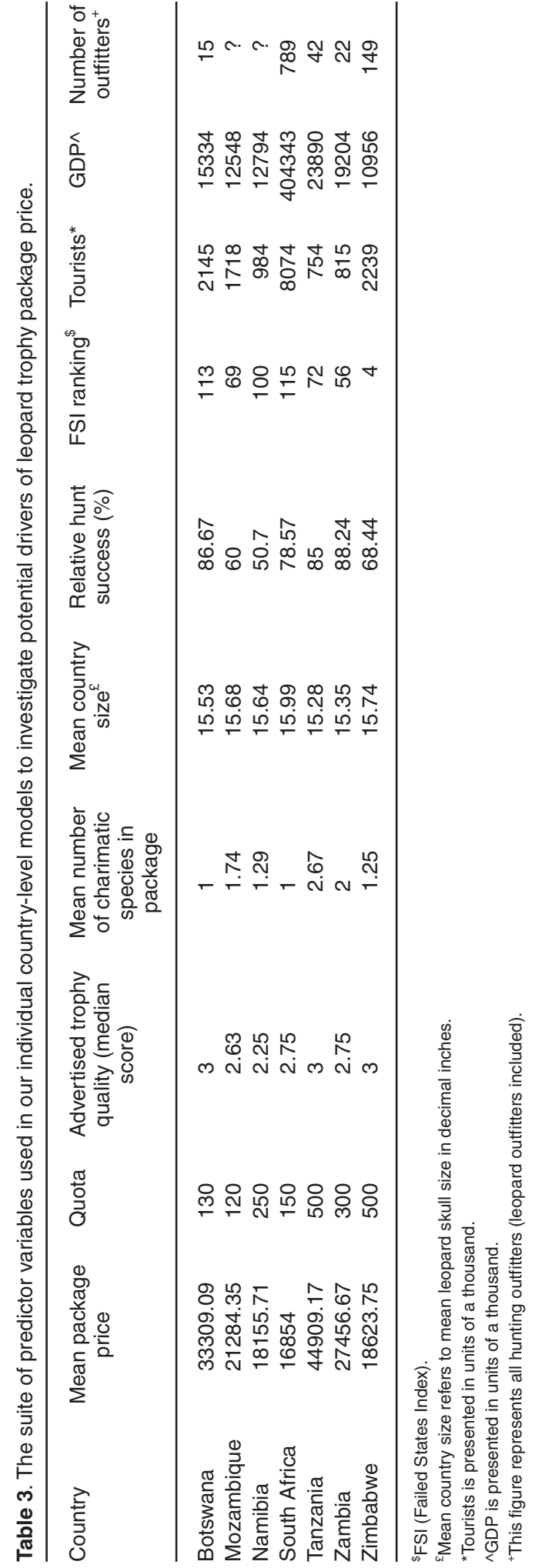


(ii) Number of charismatic species in package. As leopard hunts are often sold in combination with other game, price is likely to increase with the costs of search effort for other game. We hypothesized that package price would increase with the number of other charismatic species offered within the hunt package.

(iii) Hunt location (state, private or mixed land-use types). As governments typically charge outfitters lease fees for the use of state-owned trophy hunting blocks and for licences for tags of trophy species (including leopards), we felt it prudent to include whether outfitters hunted mainly on their own private ranches, government-owned hunting blocks or both (mixed). We hypothesized that package price would be more expensive with outfitters who hunted on state-owned land compared to those who hunted on private ranches or hunted on both.

(iv-a) Leopard trophies and (iv-b) total number of trophies. We included a measure of outfitter leopard hunting reputation indexed by the total number of leopard trophies, as well as a measure of overall hunting reputation indexed by the wildlife trophies they recorded overall (all species) in the Safari Club International (SCl) record book of big game (period from Dec 1959 - Dec 2010; http://www.scirecordbook.org, accessed July 2013). We felt that leopard records were a useful measure of reputation as leopards represent the focal species of the hunts examined in this study. However, as leopard hunt packages are often sold with other species, which may also affect a client's buying decision (indeed, leopards may not be the primary focus of a safari), we felt it prudent to also include a measure of overall outfitter reputation. We did this by recording the total number of trophies they recorded in the $\mathrm{SCl}$ record book. Records typically include the outfitter's name, hunter's name, hunt location, and guide information as well as the trophy size of the hunted species recorded in inches (for leopards, the sum of the length and breadth of the skull; presented in our analysis in decimal inches). We searched for the leopard-hunting outfitter from the package price list in our analysis and recorded the number of animal trophies they recorded. We hypothesized that outfitter leopard hunting reputation would be an important predictor of package price and this would increase with the number of leopard records recorded by an outfitter. We also hypothesized that general outfitter hunting reputation (as measured by the total number of record wildlife trophies) would be an important predictor of package price, most likely attributed to the broader experience of hunting a variety of species during the duration of the hunt.

We could not include outfitter-specific measurements of leopard trophy size from websites in our model due to shortage of records. We therefore created only a model of trophy size in our countrylevel analysis (see above).

We created a suite of candidate general linear models using these predictor variables and used Akaike's Information Criterion (AIC) to evaluate our models. (With five predictors there are 31 possible main effects models, excluding the null model.) We evaluated our models using corrected AIC (AICc) and relative model weight. This process penalizes models based upon the number of their parameters and adjusts for low sample sizes (Zar, 2013). As no single model was clearly dominant, we used model averaging to generate parameter estimates (Anderson, 2008). All statistical analyses were performed in the ' $R$ ' statistical package ( $R$ Core Team, 2014), and where appropriate means with standard error are presented as a measure of precision $(\bar{x} \pm$ S.E. $)$.

Our analyses used untransformed price (US dollars) as the response variable, diagnostic plots suggested approximately normally distributed residuals for all models. For our country-level analysis we analysed hunt price data from 92 leopard outfitters (106 leopard hunting outfitter points - due to some outfitters hunting in multiple countries) from seven countries.

\section{RESULTS}

On average, the most expensive leopard hunt packages were from Tanzania, followed by Botswana and Zambia, while the cheapest leopard hunts were offered in South Africa. Between the seven countries we found significant variation in the mean daily rates $\left(F_{(6,99)}=26.89, P<0.005\right)$, trophy fees $\left(F_{(6,99)}=9.59, P<0.005\right)$, total package prices $\left(F_{(6,99)}=36.09, P<0.005\right)$ and mean hunt duration $\left(F_{(6,99)}=6.42, P<0.005\right)$ which was the longest in Tanzania (Table 4). The majority (63\%) of packages were composed of leopard-only hunts followed by leopard and buffalo combinations (20\%). Tanzania and Zambia did not offer leopard only hunts (Fig. 1).

\section{Country-level price model}

We analysed 794 leopard trophies (mean number 
Table 4. Mean advertised hunt durations, daily rates, trophy fees and total package prices for the 106 leopard hunting outfitters in the seven countries used in our analyses.

\begin{tabular}{lccccc}
\hline Country & $\begin{array}{c}\text { Number of } \\
\text { outfitters }\end{array}$ & $\begin{array}{c}\text { Mean advertised } \\
\text { duration }\end{array}$ & Mean daily rate & Mean trophy fee & Mean package price* \\
\hline Botswana & 11 & $13.64 \pm 0.65$ & $2187.27 \pm 299.50$ & $5054.55 \pm 427.54$ & $33309.09 \pm 2871.98$ \\
Mozambique & 23 & $13.78 \pm 0.15$ & $1230.44 \pm 53.97$ & $4301.74 \pm 254.90$ & $21284.35 \pm 809.58$ \\
Namibia & 14 & $14.43 \pm 0.51$ & $905 \pm 90.77$ & $4871.43 \pm 332.40$ & $18155.71 \pm 4852.32$ \\
South Africa & 10 & $14.00 \pm 0.30$ & $651 \pm 67.07$ & $7710.00 \pm 971.76$ & $16854.00 \pm 645.54$ \\
Tanzania & 12 & $16.75 \pm 0.78$ & $2382.92 \pm 136.83$ & $4944.17 \pm 334.77$ & $44909.17 \pm 2850.68$ \\
Zambia & 12 & $13.75 \pm 0.46$ & $1722.50 \pm 160.04$ & $3687.50 \pm 304.33$ & $27456.67 \pm 2407.25$ \\
Zimbabwe & 24 & $14.08 \pm 0.06$ & $1024.17 \pm 39.01$ & $4206.25 \pm 147.24$ & $18623.75 \pm 581.55$ \\
Grand total & 106 & $14.27 \pm 0.17$ & $1371.56 \pm 68.82$ & $4758.21 \pm 167.33$ & $24471.89 \pm 1034.35$ \\
\hline
\end{tabular}

*This is the price calculated for the cheapest package on offer by an outfitter which includes a leopard trophy.

of records per outfitter $=10.59 \pm 8.90$ ) from 75 outfitter websites (mean number of records per country $=113.43 \pm 29.12$ ). Our median scores of trophy size as assessed from outfitter websites recorded per country suggested that the oldest leopards were hunted in Botswana, Tanzania and Zimbabwe (median age category $=3$ ) while the youngest leopards appeared on the websites of outfitters advertising hunts in Namibia (median category = 2.25). Our review of leopard records from the SCI record book showed that the largest leopard trophies were found within South Africa (15.99 \pm 0.08 inches; $n=201$ records) while the smallest originated from Tanzania (15.28 \pm 0.05 inches; $n=398$ records). Relative hunt success was highest in Zambia (88.24\% of attempted leopard hunts successful; $n=50$ hunt return forms) and lowest in

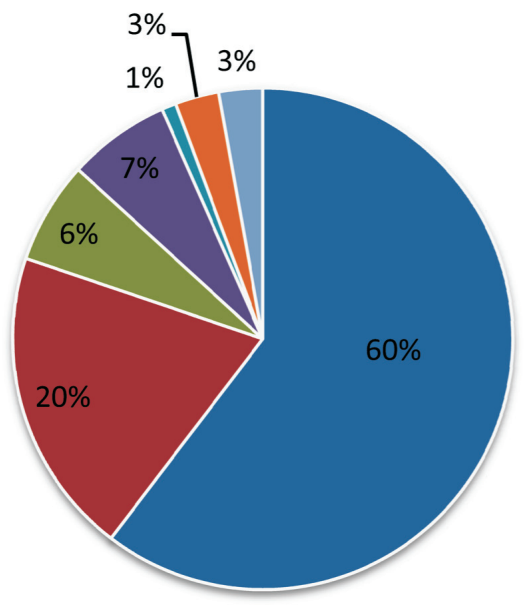

Mozambique ( $60 \%$ of attempted hunts successful; $n=20$ hunt return forms; see Table 3 for full review).

We found no correlation between mean package price for a country and the quota size of the country $\left(F_{(1.5)}=0.74, P=0.43\right)$, advertised leopard size $\left(F_{(1,5)}=2.13, P=0.20\right)$, hunt success $\left(F_{(1,5)}=3.34\right.$, $P=0.13)$, failed states index $\left(F_{(1,5)}=0.03, P=0.87\right)$ and the number of tourists visits $\left(F_{(1,5)}=1.27\right.$, $P=0.31)$. We also found no correlation between mean package price and a country's GDP $\left(F_{(1,5)}=\right.$ $0.74, P=0.43$ ) or the number of outfitters present within a country $\left(F_{(1,3)}=2.01, P=0.25\right)$. However, the mean number of charismatic species in hunt package $\left(F_{(1.5)}=4.63, P=0.08\right)$ approached significance, while mean country leopard trophy size and package price were negatively correlated $\left(F_{(1.5)}=10.28, P=0.02\right)$.

\section{Package composition}

\author{
- Leopard only \\ - Leopard/buffalo \\ - Leopard/sable \\ - Leopard/buffalo/sable \\ - Leopard/elephant/buffalo \\ - Leopard/lion/buffalo \\ - Leopard/lion/elephant/buffalo/sable
}

Fig. 1. Percentage of cheapest hunt packages which included a leopard trophy for the 106 outfitter points in our sample of 92 leopard hunting outfitters. These were the charismatic species present in the leopard trophy packages in our analyses. 
Table 5. Model components, log-likelihood and weighting scores for the six models incorporating potential predictors of cheapest leopard hunt package price.

\begin{tabular}{|c|c|c|c|c|c|}
\hline Model & d.f. & logLik & AICc & $\Delta \mathrm{AIC}$ & $\begin{array}{l}\text { Model } \\
\text { weight }\end{array}$ \\
\hline Outfitter + Charismatic species in package + All trophies & 5 & -1098.65 & 2203.89 & 0.00 & 0.36 \\
\hline Land type + Charismatic species in package + All trophies & 7 & -1094.40 & 2203.94 & 0.04 & 0.35 \\
\hline $\begin{array}{l}\text { Outfitter + Land Type + Charismatic species in package + } \\
\text { All trophies }\end{array}$ & 8 & -1093.78 & 2205.05 & 1.16 & 0.20 \\
\hline $\begin{array}{l}\text { Outfitter + Land Type }+ \text { Charismatic species in package }+ \\
\text { All trophies + Leopard trophies }\end{array}$ & 9 & -1093.36 & 2206.59 & 2.69 & 0.09 \\
\hline Outfitter + Land Type + All trophies & 7 & -1109.40 & 2233.94 & 30.05 & 0.00 \\
\hline Outfitter + Land Type + Charismatic species in package & 7 & 1110.75 & 2236.64 & 32.75 & 0.00 \\
\hline
\end{tabular}

\section{Outfitter-level package price model}

Our comparison of candidate GLM's examining potential predictors of leopard package price suggested three closely competing models (Table 5), we therefore used model-averaging to report our model coefficients. Our results suggested that leopard hunt package price increased with the number of charismatic species included in the hunt package and the total number of trophies recorded in the $\mathrm{SCl}$ record book (Table 6). There was little evidence that either land use or outfitter type were influential.

\section{DISCUSSION}

Our results indicate that leopard hunt package prices vary considerably across Africa. Notably, the variation in package price at the country level was not explained by predictors associated with product size. Package price was inversely correlated with mean country trophy size ( $\mathrm{SCl}$ record book), with South Africa having the lowest prices and yet the largest leopards, and similar trends being seen in Namibia and Zimbabwe. Prices of wildlife trophies (and even within the Felidae) are known to increase with body size for between species comparisons (Johnson et al., 2010; Palazy et al., 2011). Our results contrast with this, within a single felid species and also contrast with Lindsey et al. (2012) who suggested that the price of lion hunts in Botswana's Kalahari are particularly expensive due to the perceived size of their trophies. It is possible that leopards are smaller nearer to the equator, and interestingly, our results do lend some support for Bergmann's rule (Roberts, 1953). Outfitters from South Africa, Namibia and Zimbabwe may also be better at targeting larger leopards compared to the other four countries in our analysis, although we do not feel that so-called 'canned hunting' is responsible for the higher leopard trophy sizes in our analysis. A review on the number and trade of captive leopards in South Africa, suggests that leopards are difficult to breed in captivity, comprise few individuals and are not traded widely (Lindsey, 2010).

Table 6. Model-averaged coefficients, standard errors and critical values for our outfitter-level model examining potential predictors of leopard hunt package price in untransformed US dollars as the response variable.

\begin{tabular}{|c|c|c|c|c|c|}
\hline Parameter & $\begin{array}{l}\text { Model-averaged } \\
\text { coefficient }\end{array}$ & S.E. & Adjusted S.E. & $z$ value & $\operatorname{Pr}(>|z|)$ \\
\hline Intercept & 13571.62 & 2581.13 & 2612.09 & 5.20 & $<0.005$ \\
\hline Outfitter local & -1557.25 & 1760.20 & 1771.29 & 0.88 & 0.38 \\
\hline Species in package & 6110.88 & 1033.14 & 1044.74 & 5.85 & $<0.005$ \\
\hline All trophies & 10.83 & 2.40 & 2.42 & 4.47 & $<0.005$ \\
\hline Land Type (Mixed) & -1124.95 & 3769.74 & 3813.80 & 0.30 & 0.77 \\
\hline Land Type (Private) & -2078.54 & 2825.82 & 2850.03 & 0.73 & 0.47 \\
\hline Land Type (State) & 1028.86 & 2398.14 & 2424.68 & 0.42 & 0.67 \\
\hline Leopard trophies & 13.65 & 65.92 & 66.40 & 0.21 & 0.84 \\
\hline
\end{tabular}

Relative variable importance: All trophies Species in Package Outfitter Land type Leopard records 
As expected, our outfitter-level model examining package price variation suggested package price increases with the number of charismatic species within a leopard hunt package. Package prices used in our analysis only factored in the leopard component of a given package (i.e. duration, daily rate and leopard trophy fee - excluding the trophy fee of other species). This increase in package price may be due to the increased search, recovery and skinning costs involved in hunting other species.

Importantly, we found a positive relationship between outfitter package price and their overall hunting reputation (total wildlife trophies). This supports our second hypothesis, which stated that price may be positively correlated with overall reputation due to overall hunt experience. Outfitters may be setting their package prices in part due to their trophy hunting track record. Several studies in the economic literature suggest reputation and prominence of large firms has significant impact on the price of their products/services (Fombrun \& Shanley, 1990). For example, a seller's reputation on the online trading platform 'eBay' is an important determinant of the price of their product (Melnik \& Alm, 2002; Cabral \& Hortacsu, 2010). Leopard hunts are typically two weeks long, and the hunt itself requires prolonged time (often days) spent by the hunter and his outfitter in a hunting hide (normally stationed close to a bait). Our models provide limited evidence for the fact that the overall reputation of the outfitter is more important than the guarantee of a leopard, a high size trophy or the reputation of the outfitter as a premier supplier of leopard hunts. Instead activities such as tracking, hunting plains game, camping, eating and spending time with the hunting guide may contribute more to overall hunter satisfaction.

\section{Conservation implications}

Our results have some important consequences for the recently proposed sustainable leopard trophy hunting initiatives, which recommend the removal of older animals (Packer et al., 2009; Balme et al., 2012). Notably, population modelling suggests leopards may be safely harvested if males $>7$ years of age are targeted by hunters (Packer et al., 2009). However, our results suggest that the outfitters with the largest leopard trophies (which should be those from older animals) did not necessarily fetch the highest prices. This suggests other factors may be driving leopard trophy package price. Notably, the field costs to hunt in Tanzania and Botswana are likely to be higher than in South
Africa. This could be attributed to an extensive travel network, easy access to hunting areas, and cheaper supplies in South Africa. The majority of hunting outfitters operating in Tanzania for example fly in a considerable portion of their field supplies (Lindsey, unpubl. data). Tanzania and Botswana are also regarded as African wildernesses and classic hunting areas. It is likely that these countries aim to attract the wealthier section of the hunting market, while it is possible that smaller, fenced ranches in South Africa and Zimbabwe do not have the same selling power and aim for the lower-end of the market (Lindsey, unpubl. data).This does not totally rule out the possibility of the application of an age-based hunting programme for leopards, particularly in light of our results suggesting that outfitter overall hunting reputation was a positive determinant of package price. Lindsey, Alexander, Frank, Mathieson \& Romanach (2006) showed hunting clients are unwilling to hunt in conditions where conservation aims are compromised. We propose that if age-based hunting regulations are tested legislatively, then the more reputable outfitters may be a good market group to target. These outfitters feature a higher number of large trophies for other species and our results suggest this is one determinant of package price. With appropriate extension efforts it may be possible to motivate these outfitters to attempt better selectivity of male leopards, and with appropriate training as suggested by Balme et al. (2012), this may be possible.

Importantly, our analysis of outfitter websites also raises concerns over current hunting practices, and median country leopard age scores ranged from 2.25-3 (i.e. males between two and six years years of age). This suggests a high frequency of prime animals with territorial tenure (Bailey, 1993) are being shot by hunters. This is troubling as (a) this is considerably below the 'safe-age' limit for hunting set by Packer et al. (2009) and (b) outfitters typically advertise their best trophies on websites, and it is likely that a high proportion of younger animals are under-represented. The results from our assessment of leopard trophies on outfitter websites lend support to the findings of Spong, Hellborg \& Creel (2000) and Swanepoel et al. (2014) who also found a high proportion of sub-optimal animals (mainly females) inharvests of leopards in Tanzania and South Africa.

\section{Modelling limitations}

Our results and particularly those from our outfit- 
ter-level model should be interpreted with some caution. Firstly, our country-level analysis was limited to a small sample size and this is owed to only seven countries which offered a significant number of CITES tags. Additionally, although we made an effort to include a basic measure of living costs through GDP values, we lacked information on the living costs of each hunting outfitter and this may have provided a better fit for our package price data. A lack of this predictor variable in our outfitter model may have overemphasized the importance of some of our results, particularly the importance of outfitter reputation. Additionally, many trophy hunters also belong to a formal hunting association of some kind (e.g. SCl, Texas Trophy Hunters Association) and the community itself is well connected. It is therefore plausible that wordof-mouth advertising (e.g. Brown \& Reingen, 1987; Chevalier \& Mayzlin, 2003) and personal connections established at hunting conventions between outfitters and clients may also have an important bearing on package price. Additionally, we feel that the discrepancy in trophy size (from the $\mathrm{SCl}$ record book and websites) could be due to the side-profile presentation of the majority of photographs. Balme et al. (2012) showed that frontal presentations of the face are better for aging leopards as they show facial scarring, dewlap development and cranial size.

Ultimately, regardless of exact cause, this study highlights that the value of a trophy hunt is not merely a function of trophy size, but has multiple determinants. It is important for conservation biologists and managers to understand this complexity and look at specific drivers of value in each location, in order to best encourage compliance with more sustainable protocols for leopard trophy hunting. Finally, we suggest that future studies examine the specific proportions of trophy hunt package income and how much of this is apportioned to landowners. For example, in South Africa's KwaZulu-Natal province, it is estimated that the landowner (if he/she is not the operator) typically gets $30-50 \%$ of the total hunt package fee (currently ZAR50 000-100 000; Guy Balme, unpubl. data).

\section{ACKNOWLEDGEMENTS}

We are grateful to Panthera for financial support. We are also thankful to the two anonymous reviewers who contributed useful comments and recommendations on how to strengthen this manuscript.

\section{REFERENCES}

Anderson, D.R. (2008). Model based inference in the life sciences: a primer on evidence. London: Springer.

Ankomah, P.K. \& Crompton, J.L. (1990). Unrealized tourism potential: The case of sub-Saharan Africa. Tourism Management, 11, 11-28.

Bailey, T.N. (1993). The African leopard: ecology and behavior of a solitary felid. New York, U.S.A.: Columbia University Press.

Balme, G.A., Slotow, R. \& Hunter, L.T. (2009). Impact of conservation interventions on the dynamics and persistence of a persecuted leopard (Panthera pardus) population. Bioogical Conservation, 142, 2681-2690.

Balme, G.A., Hunter, L. \& Braczkowski, A.R. (2012). Applicability of age-based hunting regulations for African leopards. PLOS ONE, 7, e35209.

Balme, G.A., Hunter, L.T., Goodman, P., Ferguson, H., Craigie, J. \& Slotow, R. (2010). An adaptive management approach to trophy hunting of leopards Panthera pardus: a case study from KwaZulu-Natal, South Africa. In D.W Macdonald \& A.J Loveridge (Eds) Biology and conservation of wild felids (pp. 341-352). Oxford, U.K.: Oxford University Press.

Beirman, D. (2003). Restoring tourism destinations in crisis: a strategic marketing approach. Wallingford, U.K.: Cabi Publishing.

Bond, I., Child, B., De La Harpe, D., Jones, B., Barnes, J. \& Anderson, H. (2004). Private land contribution to conservation in South Africa. In B.Child (Ed.) Parks in transition (pp. 29-61). London, U.K.: Earthscan.

Booth, V.R. (2009). A comparison of the prices of hunting tourism in southern and eastern Africa. Budapest, Hungary: Food and Agriculture Organization of the United Nations.

Brown, J.J. \& Reingen, P.H. (1987). Social ties and word-of-mouth referral behavior. Journal of Consumer Research, 350-362.

Cabral, L. \& Hortacsu, A. (2010). The dynamics of seller reputation: evidence from ebay. The Journal of Industrial Economics,58, 54-78.

Coltman, D.W., O’Donoghue, P., Jorgenson, J.T., Hogg, J.T., Strobeck, C. \& Festa-Bianchet, M. (2003). Undesirable evolutionary consequences of trophy hunting. Nature, 426, 655-658.

Chevalier, J. \& Mayzlin, D. (2003). The effect of word of mouth on sales: Online book reviews. Working Paper, School of Management, New Haven, U.S.A.: Yale University.

Fombrun, C. \& Shanley, M. (1990). What's in a name? Reputation building and corporate strategy. Academic Management Journal, 33, 233-258.

Funston, P.J., Groom, R.J. \& Lindsey, P.A. (2013). Insights into the management of large carnivores for profitable wildlife-based land uses in African savannas. PLOS ONE, 8, e59044.

Harris, R.B. \& Pletscher, D.H. (2002). Incentives toward conservation of argali Ovis ammon: a case study of trophy hunting in western China. Oryx. 36, 373-381.

Hunter, L. (2012). Carnivores of the world. New Jersey, U.S.A.: Princeton University Press. 
Johnson, P.J., Kansky, R., Loveridge, A.J. \& Macdonald, D.W. (2010). Size, rarity and charisma: valuing African wildlife trophies. PLOS ONE, 5, e12866.

Jorge, A.A., Vanak, A.T., Thaker, M., Begg, C. \& Slotow, R. (2013). Costs and benefits of the presence of leopards to the sport hunting industry and local communities in Niassa National Reserve, Mozambique. Conservation Biology, 27, 832-843.

Leader-Williams, N., Kayera, J.A. \& Overton, G.L. (1996). Tourist hunting in Tanzania. Occasional paper of the IUCN Species Survival Commission No. 14.

Lewis, D.M. \& Alpert, P. (1997). Trophy hunting and wildlife conservation in Zambia. Conservation Biology, 11, 59-68.

Lindsey, P.A. (2010). A review of cheetahs and leopards in captivity in South Africa and of trade in live animals of the species. Unpublished report, University of Pretoria, Pretoria.

Lindsey, P.A., Alexander, R., Frank, L.G., Mathieson, A. \& Romanach, S.S. (2006). Potential of trophy hunting to create incentives for wildlife conservation in Africa where alternative wildlife based land uses may not be viable. Animal Conservation, 9, 283-291.

Lindsey, P.A., Roulet, P.A. \& Romanach, S.S. (2007). Economic and conservation significance of the trophy hunting industry in sub-Saharan Africa. Biological Conservation, 134, 455-469.

Lindsey, P.A., Balme, G.A., Booth, V.R. \& Midlane, N. (2012). The significance of African lions for the financial viability of trophy hunting and the maintenance of wild land. PLOS ONE, 7, e29332.

Lindsey, P.A., Balme, G.A., Funston, P., Henschel, P., Hunter, L., Madzikanda, H. \& Nyirenda, V. (2013). The trophy hunting of African lions: scale, current management practices and factors undermining sustainability. PLOS ONE, 8, e73808.

Lindsey, P.A., Nyirenda, V.R., Barnes, J.I., Becker, M.S., McRobb, R., Tambling C.J., et al. (2014). Underperformance of African protected area networks and the case for new conservation models: insights from Zambia. PLOS ONE, 9, e94109.

Loveridge, A.J., Searle, A.W., Murindagomo, F. \& Macdonald, D.W. (2007). The impact of sport-hunting on the population dynamics of an African lion population in a protected area. Biological Conservation, 134, 548-558.

Melnik, M.I. \& Alm, J. (2002). Does a seller's ecommerce reputation matter? Evidence from eBay auctions. The Journal of Industrial Economics, 50, 337-349.

Milner, J.M., Bonenfant, C., Mysterud, A., Gaillard, J.M., Csányi, S. \& Stenseth, N.C. (2006). Temporal and spatial development of red deer harvesting in Europe: biological and cultural factors. Journal of Applied Ecology, 43, 721-734.

Nelson, F., Lindsey, P. \& Balme, G. (2013). Trophy hunting and lion conservation: a question of governance? Oryx, 47, 501-509.

Nowell, K. \& Jackson, P.(1996). Status and Conservation Action Plan: Wild Cats. Gland, Switzerland: IUCN/SSC Cat SpecialistGroup, IUCN.

Packer, C., Kosmala, M., Cooley, H.S., Brink, H., Pintea, L., Garshelis, D. \& Nowell, K. 2009. Sport hunting, predator control and conservation of large carnivores. PLOS ONE, 4, e5941.

Palazy, L., Bonenfant, C., Gaillard, J.M. \& Courchamp, F. (2011). Cat dilemma: too protected to escape trophy hunting? PLOS ONE, 6, e22424.

Palazy, L., Bonenfant, C., Gaillard, J.M. \& Courchamp, F. (2012). Rarity, trophy hunting and ungulates. Animal Conservation, 15, 4-11.

R Core Team (2014). R: A language and environment for statistical computing. Vienna, Austria: R Foundation for Statistical Computing. Retrieved from: http:// www.r-project.org/ on 10 July 2014.

Ray, J.C., Hunter, L. \& Zigouris, J. (2005). Setting conservation and research priorities for larger African carnivores (Vol. 24). New York, U.S.A.: Wildlife Conservation Society.

Roberts, D.F. (1953). Body weight, race and climate. Journal of Physical Anthropology, 11, 533-558.

Saayman, M., Merwe, P.V.D. \& Rossouw, R. (2011). The economic impact of hunting in the Northern Cape province. South African Journal of Wildlife Research, 41, 120-133.

Samuelsson, E. \& Stage, J. (2007). The size and distribution of the economic impacts of Namibian hunting tourism. South African Journal of Wildlife Research, $37,41-52$.

Sönmez, S.F. (1998). Tourism, terrorism, and political instability. Annuals of Tourism Research, 25, 416- 456.

Spong, G., Hellborg, L. \& Creel, S. (2000). Sex ratio of leopards taken in trophy hunting: genetic data from Tanzania. Conservation Genetics, 1, 169-171.

Swanepoel, L.H., Lindsey, P., Somers, M.J., van Hoven, W. \& Dalerum, F. (2014). The relative importance of trophy harvest and retaliatory killing for large carnivores; a case study on South African leopards. South African Journal of Wildlife Research, 44, 115-134.

Von Brandis, R.G. \& Reilly, B.K. (2007). A temporal analysis of trophy quality in South Africa: has trophy quality changed over time. South African Journal of Wildlife Research, 37, 153-158.

Wenzel, G.W. (2011). Polar bear management, sport hunting and Inuit subsistence at Clyde River, Nunavut. Marine Policy, 35, 457-465.

Whitman, K., Starfield, A.M., Quadling, H.S. \& Packer, C. (2004). Sustainable trophy hunting of African lions. Nature, 428, 175-178.

Zar, J. (2013). Biostatistical analysis. Delhi, India: Pearson Publishers. 